\title{
Prevalência de internações hospitalares de doenças em condições sensíveis a atenção primária
}

\author{
Ortiz, E.T.; Almeida, R.J.O.; Weingartner, A.C.; \\ Apresentador: Raquel Joana de Oliveira Almeida
}

\section{Resumo}

Introdução: Condições sensíveis a atenção primaria (CSAP) do termo em inglês "ambulatory care sensitive conditions" que surgiu nos estados unidos na década de 1990. É um indicador da atividade hospitalar onde se faz o atendimento de doenças da atenção primaria em ambiente hospitalar. Acarretando um grande impacto financeiro no sistema de saúde. Material e métodos: As buscas foram realizadas em bases bibliográficas do MedLine, LILACS e PubMed com descritores, "avoidable hospital conditions", "hospitalization", "ambulatory care sensitive conditions", "preventable hospitalization", "access to medical care", "primary health care", "atenção primária", "atenção básica", "condições sensíveis a atenção primaria", onde foram avaliados 34 artigos. Resultado: Foi encontrada uma variação entre as internações por condições sensíveis a atenção primaria. No Brasil se apresenta superior a $30 \%$, excluindo partos, ( variando entre $28,1 \%$ a $42,6 \%$ ) e dependendo das regiões, em contrapartida ao encontrado em estudos espanhóis e australianos com , respectivamente, $7 \%$ a $13 \%$. Nos dados no ano de 2006 a CSAP foram responsáveis por 2.794.444 entra as 9.912.103 internações pelo SUS, correspondendo a $28,5 \%$ do total. As internações mais frequentes foram, gastroenterites e suas complicações $(23,2 \%)$, Insuficiência cardíaca(11,2\%), asma $(9,7 \%)$, doenças de vias aéreas inferiores $(7,4 \%)$, pneumonia bacteriana $(7,4 \%)$, infecções no rim e trato urinário $(7,2 \%)$, doença cérebro- vasculares $(6,5 \%)$ e hipertensão(5,2\%). Foram observados também que há maiores taxas de internação na população de baixa condição socioeconômica, extremos de idade ( $<5$ anos e $>70$ anos), variação com a oferta de serviços e não obtendo muita diferença entre os sexos, com leve prevalência do sexo feminino. Conclusão: A CSAP expõem dados interessantes em nosso pais, mostrando a necessidade de mudanças no que condiz com a atenção primaria. Realça a necessidade de uma visão mais cuidadosa para indivíduos com menos acesso e expansão dos programas de cuidado. Dessa forma evitando hospitalizações, realizando menores gastos na atenção terciaria, ficando assim em condições para incremento e aperfeiçoamento dos profissionais e do ambiente hospitalar e suas necessidades em expansão tecnológicas.

\section{Referência:}

Ortiz, E.T.; Almeida, R.J.O.; Weingartner, A.C.;. Prevalência de internações hospitalares de doenças em condições sensíveis a atenção primária. In: II Congresso Brasileiro de Medicina Hospitalar - II CBMH [= Blucher Medical Proceedings, vol.1, num.5] São Paulo: Editora Blucher, 2014. p.13

DOI 10.5151/medpro-II-cbmh-004 